\title{
Salami publication: definitions and examples
}

\author{
Vesna Šupak Smolčić
}

Clinical Institute of Laboratory Diagnostics, Rijeka Clinical Hospital Center, Rijeka, Croatia and Department of Medical Informatics, Rijeka University School of Medicine, Rijeka, Croatia

Corresponding author: vesnasupak@gmail.com

\begin{abstract}
Salami publication or segmented publication is a distinct form of redundant publication which is usually characterized by similarity of hypothesis, methodology or results but not text similarity. These aspects of publications are not objectively detected by software applications and therefore present a serious threat to publication ethics. This article presents a practical approach for dealing with manuscripts suspected of salami publication during the submission process and after article publication in Biochemia Medica.
\end{abstract}

Key words: publication ethics; redundant publication; salami publication; salami slicing; scientific misconduct

\section{Introduction}

In the last issue of Biochemia Medica, Research Integrity Corner presented the ethical problem of self-plagiarism and ways to handle such cases (1). One of the forms of self-plagiarism is segmented publication, also called "salami publication". Even though salami publication was briefly described in the previous article, recent cases of questionable publication ethics show that this type of misconduct is not recognized as such. Some of those cases involved submissions to Biochemia Medica. In order to prevent this kind of misconduct in future, it is important to inform our readership of salami publication in more detail.

Salami publication can be roughly defined as a publication of two or more articles derived from a single study (2). Articles of such type report on data collected from a single study split into several segments just large enough to gain reasonable results and conclusions, also known as "minimal publishable unit" (3).

Most readers will not fail to recognize a true "textbook" duplicate publication when they come across one. However, it is less likely that two publi- cations with no obvious text similarity, each describing different aspects of the same studied sample, will be considered as serious misconduct. From the publication ethics point of view, it is even worse because it cannot be easily detected, gives undeserved credit to authors, misleads the scientific community and directly influences clinical practice by distorting medical evidence.

\section{How to detect salami publication?}

There is no software application or algorithm for detection of salami publication. Identifying this type of publication misconduct is complex because salami publications do not often include text plagiarism so that manuscripts can easily evade strict software checking. Only under the rare circumstances of encountering both the original and the salami manuscript can some editors or reviewers suspect salami publication. Even though there are no objective ways to detect this sort of redundant publication, manuscripts suspected of being salami publications often report on identi- 
cal or similar sample size, hypothesis, research methodology and results, and very often have the same authors (4).

\section{Is salami publication always prohibited?}

There are some situations when salami publication or redundant publication is allowed. Manuscripts based on the same or similar patient sample can be published in more than one journal for a different population of readers, for example from an epidemiologist's or clinical chemist's point of view. Publication of professional guidelines in two or more different languages is also not considered to be salami or duplicate publication when it is done with the authors' or publishers' consent. Follow up investigations can be published using parts of already published results when the new manuscript largely contributes new scientific knowledge. However, in all such cases, authors are obliged to provide all necessary information to the editor in order to evaluate the justification for publishing such a manuscript. Authors must clearly state which of the presented results are already published and give the full source and consent of the original author when applicable. The added value of the new manuscript has to be properly described in the second manuscript and the extent to which two manuscripts are similar has to be easily determined. Citing the original manuscript solely by listing it in the reference section is not enough (5).

In case of large epidemiological studies or randomized controlled trials when a large amount of data is collected, it is almost impossible to present all results in a single manuscript. The number of subjects included in the study can be greater than a few thousands and longitudinal cohort studies can last for a few decades. True examples of such studies are Framingham cohort study which began in 1948 with 5209 subjects, and The Nurses' Health Study which started in 1976 with the data on 122,000 nurses $(6,7)$.

Manuscripts derived from longitudinal studies usually do not contain any overlapping results and when they are, overlaps should be minimal and always properly addressed to the already published original article. The authors must fully explain which of the presented information is already published and why is it relevant to present it again in different context.

The final decision to publish such manuscript is with the journal editor but the crucial point is the author's honesty and transparency. During manuscript submission, journals often ask the authors to confirm the originality of the submitted manuscript and so is the case in Biochemia Medica. Detection of any kind of misconduct after completing and submitting the Authors Statement (includes Authorship Statement, Statement of Originality, Research Ethics and Copyright Transfer) can be interpreted as intentional breach of publication ethics.

\section{What is the problem with salami publication?}

Salami publication is unethical for the reasons described further in this section. Authors are often advised to present the data in the simplest possible way and to focus on simple hypotheses in order to maintain the attention of the readers. For that reason many authors "simplify" their findings by splitting the results collected in a single study into several manuscripts. The exceptions when segmenting is allowed are discussed in the previous section.

Like any other form of redundant publication, salami publications artificially enlarge the number of one author's scientific work and therefore give undeserved benefit to those authors in career advancement or project funding. Greater number of articles can give a better chance for citations. Moreover, such misconduct abuses the editor's, reviewer's and reader's time and valuable publishable space at the expense of another truly original article. The ethical issues are numerous, from dishonesty to copyright violation. The most prominent reason for severe prosecution of salami publication or any form of duplicate publication is its outright influence on overall knowledge which is the basis for clinical decision making, guidelines, professional recommendations and so on. Taking the same data twice into result calculations can 
significantly distort the final outcome of metaanalysis or other systematic reviews and therefore have a direct impact on clinical practice (8).

\section{Troubleshooting salami publication}

As mentioned before, there is very small chance that the salami publication will be caught using plagiarism detection software. These are the situations where the true value of a good editor or reviewer is revealed. Conscientious readers are also of great help although it would be desirable to detect such misconduct before it reaches the readers.

In order to give better insight into potential cases of salami publication here are a few examples followed by related explanations.

Example 1: A group of authors presented preliminary results of a pilot study in the form of a short communication in one journal. Two years later, the same group of authors published an article based on a much bigger sample in the same journal. They referred to the short communication published earlier and readily presented their results which supported the hypothesis based on the pilot study. Should this be considered a salami publication?

Answer: This is certainly not a salami publication. Moreover, this is probably the best way to conduct a study. A pilot study can reveal disadvantages of a study design that can be corrected during research conduct and data collection. Cross referencing the previous publication demonstrated the authors' transparency in their intention to present the study results.

Example 2: Several groups of researchers took part in registered clinical trial on acute pancreatitis patients. The trial was designed as a longitudinal multidisciplinary study that observed diagnostic and clinical outcomes. Two groups of authors involved in this trial published two arti- cles. One article described the prognostic value of interleukin 6 on late complication development in patients with acute pancreatitis in comparison to healthy controls. The other article presented the beneficial effect of enteral nutrition in patients with acute pancreatitis. The studied population was the same but the hypotheses of both articles were completely different and with different outcomes. Should those articles be published?

Answer: Those articles can be published but under the condition that the initial research questions were different and so are the presented results. Results of one study should not overlap in any segment with another study. For example, biochemical markers presented in one article should not be presented again in the other. In addition, each article must have a unique contribution to the knowledge even though the data are collected on the same set of patients. Both manuscripts should clearly state that they present only part of the results collected from the large clinical trial and two articles must be properly cross referenced.

Example 3: A group of authors published the results of a new biomarker used in the evaluation of inflammatory bowel disease therapy. Institute's ethical committee approved the study and all patients gave informed consent to participate in the study. The sample size was small so the authors correctly chose nonparametric statistical tests. The study revealed some interesting results worthy of further follow up. Several years later the same group of authors reported results on the same hypothesis but with a different outcome and with no cross reference to the earlier publication. The studied patient population was much bigger so they used appropriate parametric statistics and in the end gained a different study outcome. Are there any grounds for suspecting salami publication? 
Answer: There are legitimate reasons for suspecting salami publication i.e., the same group of authors published two articles with the same hypothesis. The fact that the authors did not properly reference their previous work sets doubts on their good intention. There is no limitation for publishing a follow up study with a different outcome but basic conditions have to be met: clear statement of the type of the study, explanation of the differences between previous publication and the new one, and appropriate citation of the previous article.

Example 4: During research, an author presented a part of the collected data in the form of a poster presentation at a congress meeting. At the end of the year, the same author, together with his colleagues, published an article with almost the same title as the poster presentation. The hypothesis was almost the same but there were several additional parameters presented in the published article. Is this considered to be salami publication?

Answer: It is a common agreement that previous publication of a congress abstract is not considered to be duplicate publication (9). However, presenting the same poster presentation at two or more congress meetings without a clear statement of its earlier presentation is not allowed.

Example 5: A prospective study comprised of determination of C-reactive protein (CRP), procalcitonin (PCT) and serum amyloid A (SAA) in renal cancer patients. There were two groups, patients with metastatic renal cancer and patients with localized renal cancer. Within a short period of time, two articles with similar titles were published with no cross reference to each other. One article presented the use of CRP and PCT for differentiation of renal cancer stages. The other article assessed the difference of CRP and SAA between patients with metastatic and localized renal cancer. The size of the patient sample with metastatic renal cancer was different in those studies but the sample size of patients with localized renal cancer was the same and with the same demographic characteristics. Articles shared the same three authors. Could these articles be suspected of salami publication?

Answer: This is a typical case of salami publication. Exactly the same data for localized renal cancer subgroup of patients are presented in both manuscripts without appropriate reference to previously published article. In addition, there is no justified reason for splitting the data for tested biochemical markers into two separate manuscripts. However, no accusations can be made before a thorough inspection of articles involved in this case. The corresponding authors of both articles must be contacted and given the chance to make an appropriate explanation.

\section{How to avoid salami publication?}

Every research project has to be defined as clearly as possible from its very beginning. All aspects of the research process, from hypothesis, data collection, researcher's assignments and authorship criteria to manuscript submission have to be planned in advance.

Recommendations for a successful publication from the research integrity point of view are:

1. One conducted study should be reported in one article.

2. A second manuscript based on already published data should:

- properly reference the previously published article;

- besides citing the original article, clearly declare that it is part of an already published study;

- emphasize all new knowledge added in the second manuscript;

- not repeat any of the data presented in the previous article; 
- give a detailed explanation to the journal's editor on all above mentioned points because transparency is crucial.

3. Never use the same control group for more than one study. Each control group must be representative to the tested group of a single study.

\section{Biochemia Medica editorial policy - dealing with salami publication}

Biochemia Medica embraces the recommendations for dealing with redundant publication given by the Committee on Publication Ethics (COPE) $(10,11)$. In case of suspected salami publication, upon submission of the manuscript, the Journal editor will contact the author asking for an explanation. If the author's response is satisfactory, the editor will decide to proceed with manuscript processing as long as all the aforementioned criteria are met. When the author's explanation is not acceptable and there is reasonable doubt surrounding the author's good intention or when there is no answer from the author at all, the manuscript shall be rejected and either the co-authors or the authors' institution shall be informed.

In case of an already published salami article, the editor's decision depends on the amount and relevance of the duplicated data. When there is a minor redundancy, the editor will contact the author and explain the situation. When the author gives a satisfactory and honest explanation than the editor can consider publishing a correction article. Corrections have to be made in a way that properly references the original article and clearly states all overlaps with the already published data. If the amount of overlap is considered significant and there is no additional scientific value, than the editor shall contact the author explaining the need for publishing a statement of redundant publication or even retracting the article. If the author does not answer or gives an unsatisfactory explanation, the editor should contact the co-authors or the author's institution.
The final decision on acceptable similarity and the manuscript's added value to the scientific knowledge is with the editor. A decision shall never be made without attempting to contact the author and giving him the chance to make an explanation.

\section{Potential conflict of interest}

None declared.

\section{References}

1. Supak Smolcic V, Bilic-Zulle L. How do we handle selfplagiarism in submitted manuscripts? Biochem Med 2013;23:150-3. http://dx.doi.org/10.11613/BM.2013.019.

2. Abraham P. Duplicate and salami publications. J Postgrad Med. 2000;46:67-9.

3. Broad WJ. The publication game: getting more for less. Science 1981;211:1137-9. http://dx.doi.org/10.1126/science.7008199.

4. Elm E von, Poglia G, Walder B, Tramer MR. Different patterns of duplicate publication: an analysis of articles used in systematic reviews. J Am Med Assoc 2004;291:974-80. http://dx.doi.org/10.1001/jama.291.8.974.

5. Norman I, Griffiths P. Duplicate publication and 'salami slicing': ethical issues and practical solutions. Int $J$ Nurs Stud. 2008;45:1257-60. http://dx.doi.org/10.1016/j. ijnurstu.2008.07.003.

6. Framingham Heart Study. Available at: http://www.framinghamheartstudy.org/about/index.html. Accessed July 5, 2013.

7. The Nurses' Health Study. Available at: http://www.channing.harvard.edu/nhs/. Accessed July 5, 2013.

8. Alfonso F, Bermejo J, Segovia J. Duplicate or redundant publication: can we afford it? Rev Esp Cardiol 2005;58:601-4. http://dx.doi.org/10.1157/13074852.

9. International Committee of Medical Journal Editors (ICMJE). Uniform Requirements for Manuscripts Submitted to Biomedical Journals. Available at: http://www.icmje.org/ publishing_4overlap.html. Accessed August 6, 2013.

10. Committee on Publication Ethics. Flowchart: What to do if you suspect redundant (duplicate) publication (Suspected redundant publication in a submitted manuscript). Available at: http://publicationethics.org/files/u2/01A_Redundant_Submitted.pdf. Accessed July 3, 2013.

11. Committee on Publication Ethics. Flowchart: What to do if you suspect redundant (duplicate) publication (Suspected redundant publication in a published article). Available at: http://publicationethics.org/files/u2/01B_Redundant_Published.pdf. Accessed July 3, 2013. 